\title{
Globalization According to German and Brazilian Students: A Comparative Study
}

\author{
Diogo Fajardo Nunes Hildebrand \\ University of São Paulo
}

\section{Guilherme Mirage Umeda \\ University of São Paulo}

\begin{abstract}
Globalization is an extremely important phenomenon for understanding the current economic and cultural relations around the world, as well as the new forms of administration available and demanded of executives. Its very international nature, however, implies a diversity of interpretations, influenced by the "mental programming" of national cultures. Individuals subject to the values of their social groups carry with them ways of acting and thinking that are reflected in their strategic actions, a core question in the study of organizational behavior. The present study is based on a questionnaire given to university students at two leading business schools, one in Brazil and the other in Germany. Analysis of the results shows that despite the similar pattern of many responses, there are factors that set the two groups of students apart. The Brazilians tend to perceive a more direct influence of globalization on their daily lives, while a larger number Germans believe in the intrinsic equity of the globalizing process. They also feel that their country has conditions to face a globalized economy, a feeling not shared by the Brazilian students.
\end{abstract}

Palavras-chaves: globalization, education, Germany, Brazil

Received in 11/09/2005; revised in 20/09/2005; accept in 11/11/2005.

* Corresponding author:

Diogo Fajardo Nunes Hildebrand

Doutor em Marketing.

Universidade de São Paulo

Adress: Avenida dos Bandeirantes $\mathrm{n}^{\circ} 3900$ Sala 14C, Monte

Alegre, 14040900 - Ribeirão Preto - SP -Brazil

Email: diogo.hildebrand@grenoble-em.com

Telephone: (11) 30915820
Gilherme Mirage Umeda

Doutor em Educação

Escola Superior de Propaganda e Marketing

Adress: R. Álvaro Alvim, 123, Vila Mariana, 04018-010 - Sao Paulo - SP - Brazil

Email: umeda.espm@gmail.com

Telephone: (11) 50854600 


\section{INTRODUÇÃO}

o discuss globalization is to enter slippery territory, with imprecise limits whose T layers of interpretation constantly intermix and collide. An inherently multidisciplinary and polemic theme, it finds markedly different opinions both in relation to its defining characteristics and intrinsic value. Hence, it can be said that globalization slides easily between science and ideology.

In general, the technical-operational means of globalization are the frequent innovations in transportation and communications technology that accentuate the porosity of national borders. In examining the corporate dimension of global flows, we note that the presence of international organizations significantly modifies the dynamics of internal markets, starting with the arrival of foreign competition. From the viewpoint of an expanding company, it demands a radical rethinking of productive and marketing strategies. On the one hand, there is a search for new markets and better factors of production, while on the other the dispersion of marketing factors requires a profound understanding of broader and more heterogeneous publics.

Companies' responses, in this context, have direct repercussions on the lives of the people with whom they relate. We are production factors, treated as cheaper or more qualified labor; we are also consumers, served by mass or customized products. Against this globalizing backdrop, we are faced with a series of questions for which different approaches offer multiple answers: Is globalization beneficial? What is the individual's role in building more equal societies? Who are the agents responsible for globalization's expansion and configuration? Do poorer nations have a chance to choose or maneuver within this process? What are its political and cultural effects?

Global integration as observed today is a multidirectional movement, even though its systems of rewards and punishments are asymmetric. Hence, each action of one of the agents provokes a reaction from the other parties. This makes understanding the external environment one of the key characteristics of countries preparing to confront the intensification of transnational economic, cultural and political interactions.

The study of globalization, in this fashion, is an important and challenging task - for its imprecise geographic, semantic and ideological scope. This article adopts the premise that there are cultural factors underlying different nations' ways of thinking and acting. The study reported here investigated the differences and similarities of opinions between Brazilian and German university students about the globalization phenomenon. We consider this analysis to be a contribution to existing knowledge for recognizing that culture matters (citing the title of the work of HARRISON and HUNTINGTON, 2002) in the way organizations are run, and consequently in the economic development of each country and its defense of its interests and positions in the world scenario.

\section{Theoretical framework}

The topic that follows seeks to compose the theoretical bases on which our empirical study rests. First we address the controversy over the concept of "globalization", with some possible interpretations, predominantly from an economic and administrative standpoint. Then we briefly discuss the cultural influences bearing on the perception of business and its effects on management actions, using as a main reference the thinking of Hofstede (1997). 


\subsection{What is globalization?}

Various authors have proposed definitions of globalization, but no single one has become unanimous. Its multidisciplinary character hinders adopting any universal definition, since each field of knowledge has its own views and interests. This controversial element prevents a simplified treatment, whose main error is considering the phenomenon only as a breakdown of national barriers in an increasingly integrated society. Both the lowering of trade barriers and the international circulation of capital and technology are simultaneously causes and effects of the overall process, which ranges from public macroeconomic policies to the daily lives of the urban masses.

Stiglitz (2002) affirms that despite the contradiction in the importance of globalization to humanity, its meaning is quite clear: "(...) the removal of barriers to free trade and the greater integration of national economies (...)". In turn, Daniels and Daniels (1994) present a less economic and more managerial approach to the phenomenon. The authors describe globalization as the process of administering business around the world in a diverse form, balancing the characteristics of their products to the peculiar needs of each region, finding and coordinating the homogeneous anxieties of globalized individuals.

Daniels and Daniels (1994) do not restrict themselves to geography ("where I act"), reaching a definition that covers the strategic component ("how I act"). The intense and constant changes in political, economic and technical climates demand understanding globalization as more than just a simple expansion of the consumer market. The phenomenon configures the fall of frontiers as an opportunity to develop worldwide business - distributing products, building branches and vitalizing the productive/marketing process. Through globalization it is possible to use the competitive advantages of each country to create a global company that allocates its activities in the various places where they can be optimized. In summary, it is an extension of the concept of international division of labor. Dupas (2000) shares the idea of Daniels and Daniels (1994) on the matter of strengthening of organizational processes. The author demonstrates that the use of international markets becomes a possibility to maximize the local production factors, intensifying the use of intra-firm sourcing.

Other thinkers generalize the concept of globalization, thus touching on different areas of knowledge. For Beck (1999), it is a quotidian experience of the global action of the most diverse forces, such as the economy, ecology, transcultural conflicts, information or civil society. He presents the gist of his definition in the metaphor of "murder at a distance". Dicken (1998) calls attention to the relevance of space-shrinking technologies, subdivided into transportation systems (for tangible goods) and information systems (for intangibles). However, he takes the advances of science as fundamental for the development of international trade. Sustained by new technologies, a truly global company enjoys the benefits offered by each country's participation in the productive process, controlling its activities around the world.

Hirst and Thompson (1998) discuss globalization in its socioeconomic dimension. Taking as a base the dominant discourse on the phenomenon, they find laughable fragilities. For these authors, the myth of globalization, in the form it is preached by its greatest enthusiasts, can be deconstructed by differentiating between an economy that is inter-national and one that is globalized. In the first case, there is a powerful institutionalization of national economies, while in the second, there is an autonomous international system generating global determinants that have regional influence.

In inter-national economies, the connections between countries are intense, to the extent that the integration of economic agents and investments between nations progresses. 
However, this interdependence is restricted to the strategic level - the international vicissitudes do not directly affect the local economies.

In the globalized model, in contrast, systematic interdependence increases to the extent that the national reality is easily modified by external events. The authors stress the complex and fragile maintenance of a single system, able to rule all these interactions. This model demands the actuation of a hegemonic economy as a dynamic force for the whole global process, which currently has not happened.

Hirst and Thompson (1998) cite three facts that indicate a greater proximity of the current economic model to the inter-national paradigm, in detriment to true globalization: the absence of a globally accepted economic model whose characteristics sets it apart from previous ones; the dearth of precise information indicating trends toward globalization; and a frustrated attempt to perceive this process as being without precedent in world history. They emphasize this third point in discussing the historical origin of globalization. The voyages of discovery at the dawn of the modern era were determinant in developing international commerce, characteristic of mercantilism. The institution of the gold standard in the nineteenth century as the single world monetary standard, besides facilitating trade processes, is a signal that trade was already significant. For these authors, there are indications that much of the evidence so often held up to support today's globalization has been present for some time in world interrelationships.

Another contradiction exposes the fragility of a simplistic globalism: at the same time that the internationalization of commerce is so discussed, what is actually occurring is the formation of supranational trading blocks, such as the European Union and the FTAA (Hirst and Thompson, 1998). These formations tend to beget regionalized and protectionist policies, which weakens the internationalization necessary for the globalization process.

The consolidation of English as the lingua franca of international business reflects an imbalance of local forces. Chesnais (1996) stresses that the substitution of the word "mondialization" (of Latin origin) by "globalization" (Anglo-Saxon) reveals the hegemonic position of American institutions in world trade. The universal and uniform sense of globalization, which connotes a world ruled freely by the market, hides the existence of a planet that is hierarchically organized, in which the stronger countries impose asymmetric policies on the weaker ones. Chesnais (1996) suggests that the phenomenon entails a fractured organization of the world, in counterpoint to a more literal interpretation of the term's etymology.

The Brazilian geographer Milton Santos (2002) conceives of three ways of thinking of globalization: as a fable, as a perversity or as what he calls "another globalization". He argues that the globalization discourse defended and disseminated by the hegemonic logic - which asserts the universal and universalizing benefits of this moment in history - serves the clear interests of perpetuating the social and economic status quo. The preaching of the positive values generated by globalization is, according to him, an instrument of the domination of more powerful nations and economic groups, so that the concept's construct becomes illusory and hence ideological. In the same sense, Casanova (2000, p. 50) speaks of a "reversion to dependence":

The discourse of globality (...) frequently contributes to hide or hide from the effects of the neoconservative liberal policy on the countries of the Third World and the increasingly severe social problems faced by four-fifths of humanity. In the essential lines of today's world, it is indispensable to have the new of globalization, but also the old, and 
the old encompasses the world colonialism of the modern age, a global colonialism that today is neoliberal and postmodern. The reversion is in large part a recolonization.

Santos (2002, p. 19) views the current model of globalization as a perverse mechanism of inequality, since the technological advances that drive world convergence are only at the disposal of a restricted number of socioeconomic agents. Nevertheless, he believes another globalization is possible, where the technical means serve favorable and universalizing political projects. In this form, there is no moral value intrinsic to globalization, but rather to "labor and the ways of choosing the moments and the places to use" the techniques (Santos, 2002, p. 23).

Words, as signs, undergo constant redefinition, as the conventions that give them meaning change. We must guard against the pretense of the solidity of definitions, and this particularly applies to "globalization" - a recent term in the economic literature - which is evolving and historically constituted, multidisciplinary and contradictory. It is not a homogeneous, much less a universal, process, nor does it seek to eliminate all the peculiarities of each society. We assume here that globalization is a process of eliminating barriers and shortening physical and virtual distances by means of communication and transportation technologies, configuring a new international system of social, political and economic relationships.

\subsection{Culture and Management of Companies}

The controversy over the concept of globalization is not restricted to one or a few languages and cultures. While integrating technologies advance and deepen, companies, governments and people see themselves profoundly involved in the debate. Faced with the alternatives of transnational capitalism, nations must reflect in order to guide their opening or exclusion from the integrating movement. Nevertheless, the choices and the scenarios are assessed in temporally and spatially defined contexts. This item briefly discusses how national cultures generate different conceptions of the administrative and economic concepts in question. It also touches on the influences of these differences on management style and the capacity to adapt and stand out in the world economic scenario.

\subsubsection{Differences between organizational cultures and national cultures}

Starting from imprecise notions to undertake scientific studies leads to confused, and often inapplicable, conclusions. So, it is necessary, even if provisionally and arbitrarily, to assume conceptions of reality a priori. In this study, it is necessary to incorporate a vision of culture, notwithstanding the breadth of the term. The option for non-assertiveness, in this case, is allied with the realization that the social sciences are always based on moveable foundations.

Motta (1995, p. 17) lists various conceptions of the word "culture", running the gamut from the perspective of Michel Crozier of "capacity" to the anthropological viewpoint of the universe of meanings. The vision formulated by Talcott Parsons conceives of culture as a system of values. This approach agrees with the definition of Geert Hofstede, who assumes culture is "a collective programming of the mind, which distinguishes members of one group of people from another." (Hofstede, 1997, p. 5). For this author, national culture is composed of values instilled by learning, which delineate general tendencies to prefer one state of things 
to another (Hofstede, 1999, p. 38). Hence, it is assumed that by living together with likeminded people, individuals acquire patterns of behavior and thinking specific to their group.

Despite the similarity between the concepts (both authors assume values as units composing cultures), a relevant difference remains regarding the ephemeral nature of values. For Parsons (in Motta, 1995, p. 17), there is no cultural continuity over the long runs, since changes in values is a marked characteristic of modern society. In contrast, Hofstede (1999, p. 35) affirms that "cultural values differ among societies, but within a society they are surprisingly stable over the long run."

How can the paradox of organizational culture be resolved? How can one manage something that cannot change? Hofstede (1999) responds to this dilemma by establishing a difference between the concept of national and organizational cultures. If in the former values are the constituent units, in the latter this role goes to practices, which are more superficial, and hence easier to change. The use of the word "culture" in both cases generates, according to this author, a false impression that the concepts are the same.

Thus, for Hofstede (1999) the constancy of the practices within an organization can be diverted, as long as there is no conflict with the values instilled in the employees by their national cultures.

\subsubsection{The influence of culture in the perception of a concept}

At the start of the sixth chapter of his work Culture and Organizations, Hofstede (1997, p. 139-140) describes a management case study in which the executives in charge of the functional areas diverged regarding the company's policies. Citing the work of Owen James Stevens, the author observes that the students surveyed tended to present the same type of response, according to their nations of origin, when faced with the case study.

Hofstede (1997) details four measurable dimensions that differentiate cultures: distance from power; avoidance of uncertainties; masculinity/femininity; and individualism/collectivism. The first two contributed particularly to explain the students' responses in the cited case study. In France, where risk aversion and distance from power are high, and represented by a fondness for structuring by formal and hierarchical rules, the most suggested solution was to take the problem to a superior. This suggests a pyramidal organizational model. According to the author's reasoning, the response of Brazilian students should be similar to that of their French peers, given the similarities of the characteristics of the two dimensions considered.

For the Germans surveyed, the establishment of formal procedures was the preferred alternative. This choice was justified by analyzing the country's culture, which is strongly risk-averse, but with a small distance from power. The German concept of the organizational model is a well-regulated machine, without excessive verticalization.

The English, characterized by greater proximity to power and low risk aversion, identified human relationships as the problem. The solution given was to offer management classes to the employees involved in the situation. This choice stresses the importance of situational demands, in detriment to hierarchies or procedures, tracing out an organizational model similar to a "village market".

Based on the study cited above, one can conclude that culture exercises a determining influence on the way the people of one nation think about their problems and the world around them. Indeed, the infra-structural elements of a culture mold the way of thinking and lead to 
different actions. Restricting it only to a cultural factor, language presents a profound relationship with the structuring of thought. For Vanoye (1996, p. 206):

(...) it is language that molds the universe we think of, reconstructs the real, organizes it according to its laws and not the natural laws imposed from without. (...) The conception we have of the world, of others and of ourselves emanates from language. (...)... the different languages involve different systems of thinking, visions of the world, philosophies, morals, different metaphysics. Notions that appear evident or indispensable to us and that are expressed in words are, in reality, unknown to other peoples; others present totally different characteristics.

\subsubsection{Influence of culture on management of companies}

Hofstede (1999) synthetically justifies his investigation of national cultures: since administration essentially involves people, it always will be part of the culture of the societies in which it occurs. The management of companies, as a manifestation of the cultural actions of a people, shows reflections of their values and ways of thinking. Studies such as that of Prates and Barros (1997, pp. 55-69) seek to reveal the Brazilian style of managing by integrated analysis of the country's typical cultural traits.

The success of Japanese organizations in the 1970s spurred a series of attempts to explain and systematize its administrative models. The majority concluded that at the heart of this success lay Japan's culture (Morgan, 1996, p. 115). The techniques and concepts taught in business schools are not immune to the ascendancy of beliefs, values and notions (Lane, Distefano and Maznevski, 1999, p. 1). Thus, there is a representative variation in the elaboration and implementation of strategies, given a certain culture. For these authors (1999, p. 188), the relationship has dimensions that go beyond the concept of an instrumental means, configuring a determining factor of strategy. Starting from this observation, it is possible to assume that administrative methods probably extrapolate the limits of the company, as well as to perceive the interchange with the way of life of those who lead it.

Finally, it is interesting to note that not only management action, but also the administrative theories produced in a country, are influenced by its national culture (Hofstede, 1997, p. 146). In Brazil, a great part of the scientific output is strongly based on foreign references, which hinders the analysis of this effect.

\section{Field Study}

\subsection{Survey problem}

The management of companies at the start of this new century faces the complex challenge of international expansion. If the organization limits itself to its own domestic market, it is increasingly likely to confront multinationals among its main competitors. Hence, the phenomenon of globalization of the economy is an imperative for practically all economic sectors and agents.

Assuming the truth of the conception described above of the influence of culture on administrative concepts, it is possible for the meaning, causes and consequences of globalization to vary from country to country. Moreover, the impact of these perceptions should make itself felt in the way the administrators in each nation view their businesses, opportunities and threats. 
In this fashion, the research problem defined here is: What are the main differences and similarities between the opinions of German and Brazilian college students regarding globalization? The response can supply important clues about the position these future managers will adopt in their respective countries regarding the world economic scenario.

\subsection{Research method}

Our study is of a descriptive nature, based on clearly declared investigative questions. According to Cooper and Schindler (2003, p. 136), this type of survey is suitable when the objective is "descriptions of phenomena or characteristics associated with the target population (the who, what, when, where and how of a topic)."

We restricted our study universe to two academic environments. In Brazil, we prospected students at the Faculty of Economics, Administration and Accounting of the University of São Paulo (FEA/USP), regardless of their semester of study. In Germany, the respondents were drawn from business administration students at Friederich-Alexander Erlangen-Nürnberg University. Logically, these institutions are not representative of all business students in their respective countries, a fact that hinders generalizing the results as being the overall perceptions of Brazilian and German students. However, because they constitute sub-groups belonging to the broader national cultures, they are influenced by differences in values and can possibly supply evidence of their macro-environments.

The survey instrument was a self-given questionnaire, distributed both by e-mail and personally through printed copies. The invitations were also made either personally or by email, sent to address lists provided by the college registrar offices and student unions. In this way, there was no intentional sampling, but rather encouragement of spontaneous participation of all the students corresponding to the described profile. The questionnaire was originally prepared in Portuguese and translated into German. Both versions were pre-tested and adapted, contributing to their clarity and efficiency.

The questionnaire was divided into four general parts:

$>$ Description of the respondents. Personal characteristics, such as knowledge of the subject, major, semester of study, age, international experiences, etc.

$>$ Preparation for globalization. In this part, the students indicated their opinions about the needs and preparation conditions they received to confront globalization. Faced with four statements, the students had to indicate their level of agreement on a four-point scale. The pre-test indicated, however, the need to include a point for no opinion or neutrality regarding the statements. We thus decided to create a no-response option separate from the four-point scale, to discourage a central trend (as described by Cooper and Schindler, 2003 , p. 203), at the same time preserving the neutral option ${ }^{1}$.

$>$ The concept of globalization. The respondents expressed their perceptions on the most important aspects in defining the phenomenon. The question offered eight defining variables of the globalization process, among which the students had to choose and order the three they judged most important.

\footnotetext{
${ }^{1}$ Numerical scales (including that of Likert) traditionally have used a continuum with 3 to 11 points. Despite the greater use of odd numbers of points, there are situations where the researcher can choose to "force" a position, by means of even scales. We discarded this procedure due to the importance of the neutral response to this survey. Separation from the central point, as done on the questionnaire, was used as suggested by Brown (2000, p. 18) and Nowlis et al. (2000, p. 2). In fact, we observed very few cases of omission/neutral responses, which contributed to the study's body of data.
}

BBR, Braz. Bus. Rev. (Engl. ed., Online),

Vitória, v. 2, n. 2, Art. 4, p. 138 - 154, jul.- dec. 2005

www.bbronline.com.br 
$>$ Value opinions. The structure is identical to that of the second step: fourteen statements with four-point scales and a separate option indicating no opinion or neutrality. Once again, for being a subject of a technical nature, the forced taking of a position would tend to cause biases, besides representing a loss of information: a high incidence of responses such as "I don't know" could indicate, for example, a gap in the educational curriculum regarding a determined aspect of globalization.

\subsection{Presentation and analysis of the results}

We tabulated 268 questionnaires, 101 of them from Brazilian students and 167 from their German counterparts. The average age of the respondents was 22, and there was a rough gender balance: 125 women versus 140 men. Students majoring in business administration predominated in the study, due to their concentration at the German university. At FEA/USP there was a balance among the three major programs offered: administration, economics and accounting. Table 1 summarizes the personal description data:

Table 1 - Descriptive Data

\begin{tabular}{l|ccc}
\hline \multirow{2}{*}{ Item } & \multicolumn{3}{c}{ Country } \\
\cline { 2 - 4 } & Brazil & Germany & Total \\
\hline Respondents & 101 & 167 & 268 \\
\hline Average age & 23.4 & 22.2 & 22.7 \\
\hline Major & & & \\
$\quad$ Administration & 39 & 117 & 156 \\
Economics & 31 & 16 & 47 \\
Accounting & 28 & 0 & 28 \\
Social Sciences & 2 & 29 & 31 \\
Others & 1 & 5 & 6 \\
\hline Sex & & & \\
Female & 43 & 82 & 125 \\
Male & 57 & 83 & 140 \\
\hline International experience & & & \\
Yes & 33 & 55 & 88 \\
$\quad$ No & 67 & 111 & 178 \\
\hline Occupation & & & \\
Multinational company & 30 & 28 & 58 \\
National company & 43 & 42 & 85 \\
Do not work & 27 & 95 & 122 \\
\hline
\end{tabular}

The item "international experience" asked the students whether they had ever lived abroad or participated in some type of exchange program. The percentage incidence in both countries was exactly the same: $33 \%$ affirmative. The "occupation" item asked whether the students worked or had worked (possibly as interns) in national or multinational companies. Percentage-wise, those with no work experience were more representative in the German sample: 58 versus 27 in Brazil. Of those who worked, more did so at national companies in Germany than in Brazil. We suppose this result is due to the greater business strength of European organizations.

When asked about their level of knowledge of globalization, the students demonstrated security in the majority of cases. A greater number of German students responded that they knew little about globalization in comparison with the Brazilians. 
This is not necessarily an indication of greater knowledge by the Brazilian students, since the answer called for a subjective self-evaluation by the respondent. Various cultural factors can generate differences of perception, independent of the real level of knowledge, not considered here. There was also a positive correlation $(0.328$, with greater than $1 \%$ significance) between the age and level of knowledge, with the older students more cognitively prepared to judge themselves.

Table 2 - Level of Knowledge About Globalization

\begin{tabular}{l|ccc}
\hline \multirow{2}{*}{\multicolumn{1}{c|}{ Knowledge (\%) }} & \multicolumn{3}{c}{ Country } \\
\cline { 2 - 4 } Great & Brazil & Germany & Total \\
Reasonable & 45.5 & 22.1 & 31.3 \\
Small & 50.5 & 57.0 & 54.6 \\
\hline
\end{tabular}

\subsubsection{Preparation for globalization}

Table 3 summarizes the results for the statements dealing with the students' preparation to face the reality of a globalized economy.

Table 3 - Preparation for Globalization

\begin{tabular}{l|ccc}
\hline \multirow{2}{*}{ Preparation for globalization (\%) } & \multicolumn{3}{c}{ Country } \\
\cline { 2 - 4 } Specific preparation is necessary & Brazil & Germany & Total \\
Disagree & 11.0 & 17.5 & 15.0 \\
Agree & 89.0 & 82.5 & 85.0 \\
\hline The university has prepared me well & & & \\
Disagree & 45.5 & 19.5 & 29.6 \\
Agree & 54.5 & 80.5 & 70.4 \\
\hline The media povide inforation & \multicolumn{3}{|}{} \\
Disagree & 46.5 & 48.5 & 47.7 \\
Agree & 53.5 & 51.5 & 52.3 \\
\hline Ifeel prepared for globalization & \multicolumn{3}{|c}{} \\
Disagree & 28.0 & 24.0 & 25.5 \\
Agree & 72.0 & 76.0 & 74.5 \\
\hline
\end{tabular}

There was a strong tendency for both student groups to feel they need specific preparation to face the challenges of globalization. However, the adaptation of their schools to this important factor was seen differently between the country samples: the chi-square test statistic of 20.1 indicates that one cannot reject the null hypothesis that there was no influence of country on the response to the corresponding item. The great majority of German students $(80.5 \%)$ felt their school was suitably adapted in the globalized context, while among Brazilian students the affirmative proportion was smaller, albeit still in the majority (54\%). The opinion on the sufficiency of information furnished by the mass media was very divided, near symmetric for both countries.

The statement "I feel prepared for globalization" elicited similar percentages between the samples (without significant differences) of approximately $75 \%$ agreement. If at first glance this result could seem strange against the $31 \%$ who stated they had great knowledge of globalization, a correlation analysis generates a reasonable interpretation. Measuring the relationship among the questions (by means of the Spearman index, due to the ordinal nature 
of the scales) reveals a positive index of 0.264 , significant at the $1 \%$ level. Hence, it can be inferred that the knowledge of globalization represents nearly $26 \%$ of the preparation to face it: the students who perceived that, apart from the cognitive dimension, there are other elements essential to practice global administration. We can identify, for example, abilities and attitudes as fundamental and non-cognitive spheres in the process of learning business management.

\subsubsection{What is globalization?}

In the test to define globalization, each respondent was asked to choose and order three factors considered most relevant in the conception of the phenomenon. The most important received three points and the third most important one point. The others received no points. The table below shows the results of summing for each item.

Table 4 - Definition of Globalization

\begin{tabular}{l|ccc|c}
\hline & \multicolumn{3}{|c|}{ Sum of points (1 to 3) } & \multicolumn{2}{c}{ Order } \\
\cline { 2 - 5 } Globalization is a phenomenon: & Brazil & Germany & Total & Brazil Germany \\
\hline Of more intense commercial relations among countries. & 132 & 281 & 413 & 1 \\
Of growing systemic interdependence among nations. & 124 & 127 & 251 & 2 \\
That defines a new form of administration, expanding the & & & & \\
Opportunity for business for everyone. & 74 & 154 & 228 & 4 \\
Of shortened distnces, thanks to new transportation and & & & & \\
communication technologies. & 121 & 97 & 218 & 3 \\
Of economic internationalization free of interventions. & 22 & 96 & 118 & 6 \\
Of elimination of fiscal barriers between countries. & 10 & 101 & 111 & 8 \\
Of total integration of all nations on the planet. & 22 & 66 & 88 & 6 \\
That covers various areas of knowledge. & 35 & 47 & 82 & 6 \\
\hline
\end{tabular}

The most important aspect in defining the phenomenon of globalization, according to the students, was intensification of the commercial relations among countries. Also important were growing systemic interdependence and new possibilities of administration. Finally, the shortening of distances due to space-reducing technologies closed out the first half of aspects, which accounted for $75 \%$ of the points - for Brazilians $84 \%$ while for Germans $68 \%$.

Disregarding the order of importance and computing only the number of mentions, it is possible to conduct adherence tests to detect the factors that most set the Germans apart from the Brazilians. The definition "more intense commercial relations among countries" was much more relevant for the Germans, as was "economic internationalization free of interventions." In contrast, the definition "shortened distances thanks to new technologies" was considered more important to the Brazilian students. This result is a reflection of the geographic and political-economic configurations of the two countries. Brazil's continental dimensions, its precarious logistics infrastructure and the distance from large world consumption centers makes shortening distances an essential factor for the country's entry into the logic of transnational markets. Germany, on the other hand, is in the middle of the European continent and suffers few of these logistics and distance problems. Moreover, the consolidation of the European Union is a stimulus to the flow among the continent's nations, placing German citizens and companies in more intense contact with international agents. In this form, the most significant barrier to that country's integration in the world system consists of its borders, in the more concrete form of governmental interventions in the economic circle and in the very dynamic of competition among international organizations. 


\subsubsection{Opinions on the phenomenon of globalization}

Table 5 summarizes the respondents' opinions on globalization. We divided the conclusions presented between the countries and then totaled the set of the two samples. The last column indicates the existence or not of statistically significant differences, measured by chi-square tests at less than $1 \%$ levels of significance.

Table 5 - Opinions on Globalization

\begin{tabular}{|c|c|c|c|c|}
\hline \multirow[b]{2}{*}{ Globalization: } & \multicolumn{3}{|c|}{ Concordance (in \% valid) } & \multirow{2}{*}{$\begin{array}{l}\text { Is there a statistica } \\
\text { difference }\left(\text { chi }^{2}{ }^{2}\right) \text { ? }\end{array}$} \\
\hline & Brazil & Germany & Total & \\
\hline Has worsened by quality of life & 22,4 & 7,6 & 13,3 & Yes \\
\hline Promotes the distribution of income among nations. & 10,9 & 38,0 & 27,7 & Yes \\
\hline Is a passing phenomenon. & 3,0 & 4,3 & 3,8 & No \\
\hline Is important to my country's development. & 82,2 & 81,8 & 82,0 & No \\
\hline Is beneficia for humanity as a whole. & 52,6 & 45,5 & 48,1 & No \\
\hline My country is prepared for globalization. & 22,8 & 69,7 & 51,2 & Yes \\
\hline Is inevitable. & 92,1 & 88,1 & 89,7 & No \\
\hline Benefits only the developed countries. & 60,0 & 61,0 & 60,6 & No \\
\hline Is an old phenomenon. & 70,8 & 20,1 & 39,6 & Yes \\
\hline Is not an imposition, but rather a choice. & 11,0 & 34,0 & 25,0 & Yes \\
\hline Diectly affects my life. & 94,0 & 65,6 & 76,7 & Yes \\
\hline Has imprved my quality of life. & 71,6 & 55,8 & 62,0 & Yes \\
\hline Promotes the distribution of income within countries. & 10,2 & 23,4 & 18,1 & No \\
\hline Is generally positive. & 69,9 & 76,8 & 74,2 & No \\
\hline
\end{tabular}

There are three statements whose results stand out, with similar response patterns in the two survey universes: according to the students, globalization "is inevitable"; "is important for the country's development"; and is not "a passing phenomenon". At the same time it is imperative, economic globalization appears to represent a possibility for progress, of placement of countries in meritorious positions in the new international organization of labor. The conscious and meticulous adhesion of nations to this imminent long-term phenomenon can represent a redefinition of roles in the world economy, where the most prepared will stand out. The constructive potential of globalization is reflected in the statement "it is generally positive", with which $74.2 \%$ of all respondents agreed.

The statement "is not an imposition, but rather a choice" presented a statistical difference in the chi-square test for the two countries. Although the great majority of students from both countries corroborated the statement of inevitability described above, significantly more Germans agreed with the facultative entry into the globalization process. A hypothesis for this attitude is the greater bargaining power of developed countries in international economic negotiations or the invisible duel of acculturation. Brazil, in a more precarious position in the world economy and with less independence vis-à-vis its developed trading partners, sees itself as having less room for action.

Approximately $20 \%$ of the Brazilian respondents considered that globalization, as it is structured today, has caused a decline in their quality of life. The check statement "improved my quality of life" confirms that the majority (71\%), in contrast, see globalization as a base to improve their living conditions. In Germany, in contrast, there were more conflicting responses to the two assertions (Table 6). Only $7 \%$ of the sample alleged globalization has worsened their quality of life; the index for improved life quality was $56 \%$. How can these results be explained? The considerable incidence of conflict between opposite assertions in Germany can indicate a less resolute position on the pros and cons of globalization on the 
population's life quality. The interview subjects may have been imaging specific situations of improvement and degeneration at the moment of each question, demonstrating that there is not a single deterministic feeling on globalization's influence. The greater agreement of the Brazilian students in relation to improved quality of life can reflect the intense changes in the country since opening its economy at the start of the 1990s. The widespread consumption of imported products is a recent reality for most Brazilians, accustomed to a very small number of options before the opening. On the other hand, Germans (particularly in the western part) already had access to flows of goods, services, people and ideas from outside its borders before the unification process, occurring at very nearly the same time as Brazil's economic opening. Regarding a worsened life quality, the greater agreement of Brazilian students can indicate concern with the country's poor income distribution. If the 1990s was a decade when Brazilian consumers entered the world market, it was also a period of worsening income disparity. The social effects of this perverse phenomenon reflect on the quality of life of all citizens, since living in society presupposes human relations highly influenced by people's surroundings. Social inequality, for example, generates poverty, which in turn causes violence, an ever-present blight in both Brazil's cities and countryside.

\begin{tabular}{|c|c|c|c|c|c|}
\hline \multirow[b]{2}{*}{ Country } & & & Wors & $\mathbf{Q L}$ & \multirow{2}{*}{ Total } \\
\hline & & & Disagree & Agree & \\
\hline \multirow{3}{*}{ Brazil } & \multirow{3}{*}{ Improved QL } & Disagree & 9 & 18 & 27 \\
\hline & & Agree & 63 & 4 & 67 \\
\hline & & Total & 72 & 22 & 94 \\
\hline \multirow{3}{*}{ Germany } & \multirow{3}{*}{ Improved QL } & Disagree & 52 & 8 & 60 \\
\hline & & Agree & 79 & 2 & 81 \\
\hline & & Total & 131 & 10 & 141 \\
\hline
\end{tabular}

Remark: Numbers in bold represent conflict cells.

The statement "directly affects my life", which also presented significant differences according to the chi-square test, corroborates this analysis. When there is a perception that globalization has in some way altered people's individual conditions, one would expect greater precision in identifying the ways this has been for better and for worse. The German students, in concurring less with this assertion, showed that the effects on life quality are not directly verifiable, and hence it is harder to discern whether they are positive or negative. The confirmation of this hypothesis can be verified in Table 7: 72\% of the Germans surveyed who disagreed with the statement "directly affects my life" present a conflicting pattern of responses to the life quality assertions - for those who concur, the index is only $20 \%$. 
Table 7 - Cross-reference among the three assertions: "Directly affects my life", "Has improved my quality of life" and "Has worsened my quality of life" (Germany)

\begin{tabular}{c|cl|cc|r}
\hline \multirow{3}{*}{ Affects my life } & & & \multicolumn{2}{|c|}{ Improved QL } & \multirow{2}{*}{ Total } \\
\hline \multirow{3}{*}{ Disagree } & & Disagree & Agree & \\
& Worsened QL & Disagree & $\mathbf{3 4}$ & 10 & 44 \\
& & Agree & 3 & & 3 \\
& & Total & 37 & 10 & 47 \\
\hline \multirow{3}{*}{ Agree } & Disagree & $\mathbf{1 6}$ & 67 & 83 \\
& \multirow{2}{*}{ Worsened QL } & Agree & 5 & $\mathbf{2}$ & 7 \\
& & Total & 21 & 69 & 90 \\
\hline
\end{tabular}

The problem of income distribution in Brazil can condition other results of the investigation. In the statement "promotes distribution of income among countries," there was a significant difference in the index of agreement, $10 \%$ in Brazil versus 38\% in Germany. Once again, Brazil's lesser bargaining power in the international scenario can lead to a perception by Brazilian students that the flow of resources in the globalized economy is unequal, widening the gap between rich and poor.

The competitiveness of nations, expressed by the assertion "my country is prepared for globalization," confirms the difference between the two countries. While only $22 \%$ of the Brazilian students saw their country in a favorable position to compete internationally, approximately $70 \%$ of Germans saw their nation as ready for this challenge. The chi-square result of 53.8 shows the significant difference between the samples. Lambda, a measure of association based on the chi-square, indicates the improvement in the prediction of one variable based on another. With the statement as the dependent variable and the country of origin as the independent, there was a $44 \%$ improvement in the predictions, i.e., knowing in advance what country a respondent was from significantly expanded the number of correct predictions for the assertion "my country is prepared for globalization." This results makes intuitive sense: Brazilians and Germans have a realistic perception of the objective conditions of their respective countries in the political, cultural and economic game of globalization.

It is interesting to examine the statement "is an old phenomenon" because it presented a difference in the adherence test. The greater proportion a German students majoring in business administration can be a bias factor for many of the conclusions reported above. In other words, the differences between the samples could be related to the distribution of degree programs chosen rather than the respondents' nationalities. To verify this possibility, we carried out chi-square tests of adherence separating the respondents into Administration and Others - the grouping of all other majors into one category equalized the size of the samples, improving the statistical results. No statement showed statistically significant differences, except "is an old phenomenon." However, one can formulate the hypothesis that the greater presence of German students studying business administration in the sample influenced the chi-square test for the two countries. Perhaps a justification for this is the predominance of economic and social theories over administrative ones, which trace their historical origins to the phenomenon of globalization, as seen in the bibliographical review of this text. 


\section{Conclusions}

Globalization is an inevitable theme. It is present in schools, companies and the mass media. The term already is part of a public agenda, widely debated in all sectors of society. For this reason, studying it involves interest in contemporaneous questions and patience in the face of results that are not always immediate. The conclusions of this article are only vestiges of a phenomenon, read through the perceptive filter of the surveyrespondents.

The results corroborate the studies of Hofstede (1997), according to which national cultures have within them intrinsic ways of acting and thinking that define the social groups to which they belong. The different cognitive models of each country are also responsible for distinct ways of perceiving the world, and consequently, of acting in it. Regarding economic relations, national cultures may influence the particular modes of administration, in such a way that the study is justified as an effort to understand the functioning of partnerships and competitions on a global scale.

This study found differences in the way a sample of German students and another of Brazilian students perceive the globalization phenomenon, from its definition to its consequences for daily life. The significant weight of historical and geographic factors was noticeable, for example, in the creation of a conception of the term. While the question of shortening distances was fundamental to Brazilians - physically apart as they are from the larger world market - the Germans stressed the intensification of commercial exchanges and reduction of governmental interferences on the actions of the market.

At the same time its inevitability figures as a fulminating characteristic of globalization, the reflections of this macro-environmental movement on peoples' daily lives was seen differently in the two countries. Brazilians considered globalization as a direct influence on their individual lives, suddenly surrounded by the consumption of goods, services and ideas simultaneously exchanged the world over. Germans, in their long history of flows throughout the European continent (one need only remember the influence of the Germanic invasions on the consolidation of the Middle Ages) and their economic power alternately built up and toppled over, did not perceive the effects of globalization so directly.

Regarding the equity of the globalization process, more German students expressed optimism than Brazilians. Living with the perverse effects of one of the world's worst income distributions may well have affected the world view of the Brazilian students, witnesses to countless economic oscillations that have only enlarged the gap between rich and poor. Seeing their country as among the weak, fewer Brazilians tend to believe in globalization as a means to a better distribution of wealth among nations.

According to the same scenario, the perception of national competitiveness among their students represents an important distinction between the two countries. Germans, in a more comfortable international situation than Brazilians, consider their country up to facing the challenges of globalization.

The results of this study supply indications that indeed can help in the comprehension of economic and administrative research. Its objective was not to define globalization or pose hypotheses about the current conditions of the phenomenon. Rather, its focus was on the opinions of students who, as part of the next generation of business leaders, can influence the development of the national and international economies. It is these opinions, mirrored in models of action, that will bit by bit structure the organizational relations around the world, defining what globalization will be, not now, but in the future. 
Other studies can build on this one. Broader surveys, covering more countries in more detail and/or involving more schools, can be valuable to generalize and validate these results. Studies with presently serving executives would help get a handle on the current vision of globalization in the market. A better qualitative understanding of the countries involved would be very valuable, since it could indicate motivations behind the positions objectively measured by the questionnaire.

It is also worth remembering, finally, that the present study had some limitations pointed out here. First, the proportion of students studying business administration in the German sample was far higher than among the Brazilian students, reflecting the real proportion in the German university. One cannot discard the possibility that some national differences were skewed by this different profile of student majors. Second, the restricted number of teaching institutions makes it impossible to generalize the results to all German and Brazilian students. There also may be biases in the colleges, in the form of ideological lines, homogeneous characteristics of the public and composition of the faculties. Finally, the ordinal scales used here did not permit the use of parametric tests, which restricted the analytic possibilities of the data.

\section{References}

BECK, Ulrich. O que é globalização? Equívocos do globalismo, respostas à globalização. São Paulo: Paz e Terra, 1999.

BROWN, J. D. What issues affect Likert-scale questionnaire formats? JALT Testing \& Evaluation SIG Newsletter, v. 4, n. 1, April 2000, pp. 18-21.

CASANOVA, Pablo González. Globalidade, neoliberalismo e democracia. In: GENTILI, Pablo (org.). Globalização excludente. 4th ed. Petrópolis, RJ: Vozes / Buenos Aires: CLACSO, 2000.

CHESNAIS, François. A mundialização do capital. São Paulo: Xamã, 1996.

COOPER, Donald R. and SCHINDLER, Pamela S. Métodos de pesquisa em administração. 7th ed. Porto Alegre: Bookman, 2003.

DANIELS, J. and DANIELS, N. Visão Global. São Paulo: Makron Books, 1996.

DICKEN, Peter. Global Shift: the internationalization of economic activity. 3rd ed. New York: Guildford Press, 1998.

DUPAS, Gilberto. Economia global e exclusão social: pobreza, emprego, Estado e o futuro do Capitalismo. 2nd ed. São Paulo: Paz e Terra, 2000.

HARRISON, Lawrence E. and HUNTINGTON, Samuel P. A cultura importa: os valores que definem o progresso humano. Rio de Janeiro: Record, 2002.

HIRST, Paul and THOMPSON, Grahame. Globalização em questão: a economia internacional e as possibilidades de governabilidade. Petrópolis: Vozes, 1998. 
HOFSTEDE, Geert H. Cultures and Organizations: Software of the mind. New York: McGraw-Hill, 1997.

. Problems remain, but theories will change: the universal and the specific in $21 \mathrm{st}-$ century global management. Organizational Dynamics, 1999, pp. 34-44(1999).

LANE, Henry W., DiSTEFANO, Joseph J. and MAZNEVSKI, Martha L. International Management Behavior. Lane, DiStefano and Maznevski, 1999

MORGAN, Gareth. Imagens da organização. São Paulo: Atlas, 1996

MOTTA, Fernando C. P. Cultura nacional e cultura organizacional. Revista da ESPM, Aug. 1995, pp. 17-23.

NOWLIS, Stephen M., KAHN, Barbara E. and DAHR Ravi. Indifference versus Ambivalence: The Effect of a Neutral Point on Consumer Attitude and Preference Measurement.

PRATES, M. A. S. and BARROS, B. T. de. O estilo brasileiro de administrar. São Paulo: Atlas, 1997.

SANTOS, Milton. Por uma nova globalização: do pensamento único à consciência universal. 9th ed. Rio de Janeiro: Record, 2002.

STIGLITZ, Joseph. A globalização e seus malefícios: a promessa não cumprida dos beneficios globais. São Paulo: Futura, 2002.

VANOYE, Francis. Usos da linguagem: problemas e técnicas na produção oral e escrita. 10th ed. São Paulo: Martins Fontes, 1996. 